\title{
Lipid Peroxidation by Human Blood Phagocytes
}

\author{
Thomas P. Stossel, Robert J. Mason, and Arnold L. Smith \\ From the Divisions of Hematology-Oncology and Infectious Diseases, Children's Hospital \\ Medical Center, and the Department of Pediatrics, Harvard Medical School, \\ Boston, Massachusetts 02115 and Cardiovascular Research Institute, \\ San Francisco, California 94143
}

A в S T R A C T Cell suspensions enriched in human blood monocytes, obtained from normal peripheral blood by sedimentation on sodium diatrizoate-Ficoll gradients or from the blood of patients with neutropenia and monocytosis, accumulated malonyldialdehyde, a labile catabolite of lipid peroxidation, during incubations with polystyrene beads or heat-killed Staphylococcus epidermidis. Mixed blood leukocytes principally composed of granulocytes or granulocytes purified by density gradient sedimentation did not accumulate malonyldialdehyde during incubations with these particles, but did when ingesting particles containing linolenate. The phospholipid fatty acid composition of monocyte-enriched and purified granulocyte preparations from the same donors were compared. The molar fraction of arachidonate $(20: 4)$ in phospholipids from monocyte-rich preparations was $62 \%$ greater than that of purified granulocytes. The findings indicate that human monocytes, possibly because of a greater content of polyunsaturated fatty acids in their membranes, peroxidize a greater quantity of endogenous lipids than granulocytes during endocytosis. Normal human granulocytes have the capacity to peroxidize ingested lipids. However, mixed leukocytes from two patients with chronic granulomatous disease produced little malonyldialdehyde when engulfing linolenate-containing particles. Therefore the capacity to peroxidize lipid is related to cellular oxygen metabolism, a function in which chronic granulomatous disease granulocytes are deficient.

Malonyldialdehyde chemically prepared by hydrolysis of tetramethoxypropane, by extraction from peroxidized linolenic acid, or purified from extracts of phagocytizing rabbit alveolar macrophages had bactericidal activity against Escherichia coli and $S$. epidermidis. Therefore, toxic catabolites of lipid hydroperox-

Dr. Stossel is an Established Investigator of the American Heart Association.

Received for publication 21 February 1974 and in revised form 15 May 1974. ides may potentiate the bactericidal activity of hydrogen peroxide in mononuclear phagocytes.

\section{INTRODUCTION}

Polymorphonuclear leukocytes, monocytes, and macrophages metabolize oxygen to produce hydrogen peroxide and toxic radicals during ingestion of particles (1). These oxygen metabolites are synthesized by phagocytes for use in reactions that kill ingested microorganisms $(2,3)$. A potential consequence of these oxidative reactions in phagocytes is the peroxidation of endogenous lipids. Peroxidation of membrane phospholipids of phagocytizing rabbit alveolar macrophages and of guinea pig polymorphonuclear leukocytes has been documented by iodometric analysis (4). Rabbit alveolar macrophages ingesting inert particles accumulated malonyldialdehyde, a labile catabolite of certain fatty acid hydroperoxides, suggesting that intense peroxidation of endogenous lipids occurred (4). Guinea pig morphonuclear leukocytes, which contained five times less arachidonate in their phospholipids than rabbit alveolar macrophages, did not accumulate malonyldialdehyde during engulfment of inert particles. However, the polymorphonuclear leukocytes did accumulate the aldehyde when fed particles containing a polyunsaturated fatty acid (4).

The present study was undertaken to determine whether human polymorphonuclear leukocytes or monocytes generate malonyldialdehyde during engulfment of particles, and to correlate the presence or absence of its accumulation with the fatty acid composition of cellular phospholipids. The role of oxygen metabolism in lipid peroxidation was assessed by analyzing whether neutrophils from patients with chronic granulomatous disease, phagocytes that do not enhance oxygen consumption or hydrogen peroxide production during ingestion (5), could peroxidize polyunsaturated fatty acids incorporated into ingestible particles. In light 
of the known antimicrobial activity of aldehydes (3), malonyldialdehyde, prepared in several ways including purification from extracts of phagocytizing rabbit macrophages, was tested for bactericidal activity.

\section{METHODS}

Preparation of human leukccyte suspensions for analysis of malonyldialdehyde production. Mixed leukocytes were isolated from peripheral blood anticoagulated with acidcitrate-dextrose (NIH formula A), as previously described (6). This procedure included removal of erythrocytes by sedimentation with dextran and lysis with ammonium chloride, and washing of the leukocytes with $0.15 \mathrm{M} \mathrm{NaCl}$. The subjects from whom the blood was obtained were normal humans, patients in whom a diagnosis of chronic granulomatous disease was established (6), two patients with idiopathic thrombocytopenic purpura $(10,000$ and 17,000 platelets $/ \mathrm{mm}^{3}$, and individuals with congenital or acquired neutropenia $\left(0-300\right.$ neutrophils $\left./ \mathrm{mm}^{3}\right)$ with monocytosis $\left(1,300-6,400\right.$ monocytes $\left./ \mathrm{mm}^{3}\right)$. Suspensions of cells rich in erythrocytes plus granulocytes, or else monocytes plus lymphocytes and platelets, were prepared from normal human peripheral blood by gradient centrifugation on Ficoll (Pharmacia Fine Chemicals, Uppsala, Sweden)-sodium diatrizoate (Winthrop Laboratories, Div. of Sterling Drug, Inc., New York), according to the procedure of Böyum (7). Erythrocytes were removed from the granulocyte-rich fraction by sedimentation in $1.5 \%$ dextran in $0.15 \mathrm{M} \mathrm{NaCl}$, followed by brief exposure to $0.2 \% \mathrm{NaCl}$. These suspensions were designated "purified granulocytes", and contained $92 \%$ neutrophils and $8 \%$ eosinophils (average of 20 preparations). The platelet content of the monocyte-lymphocyterich fraction was diminished by repeated differential centrifugation of the cells in $0.15 \mathrm{M} \mathrm{NaCl}$ at $200 \mathrm{~g}$ for $10 \mathrm{~min}$.

Preparation of human leukocytes for lipid analysis. To separate "monocytes" 1 and polymorphonuclear leukocytes from the same donor for lipid studies, the usual method for collecting cells was altered. $450 \mathrm{ml}$ of blood was withdrawn into heparinized plastic syringes. The blood was centrifuged at $300 \mathrm{~g}$ for $15 \mathrm{~min}$, the plasma removed and centrifuged at $800 \mathrm{~g}$ for $10 \mathrm{~min}$ to remove the majority of the platelets, and the blood reconstituted. The granulocyte-erythrocyte fraction was separated from the monocytes and "lymphocytes" by gradient centrifugation on Ficoll-sodium diatrizoate (7). Erythrocytes were removed from the granulocytes by dextran sedimentation and lysis with $0.2 \% \quad \mathrm{NaCl}$ (9). The monocytes were concentrated by allowing the cells to adhere to plastic $\left(150-\mathrm{cm}^{2}\right.$ petri dishes-Falcon Plastics, Division of B-D Laboratories, Inc., Los Angeles, Calif.) for $2 \mathrm{~h}$ at $37^{\circ} \mathrm{C}$ in minimal essential medium containing Hanks' buffer solution and $15 \%$ fetal calf serum (Grand Island Biological Co., Grand Island, N. Y.). The nonadherent cells (lymphocytes) were removed by washing the dishes three times with Hanks' buffer solution containing calcium and magnesium. The monocytes were recovered by washing twice with Hanks' buffer solution without added calcium and magnesium but with $5 \mathrm{mM}$ EDTA. From $450 \mathrm{ml}$ of blood, the yield of monocytes was approximately $2 \times 10^{7}$ cells with a range of purity from 50 to $75 \%$. The major contaminants were lymphocytes, although some neutrophils

1 "Monocytes" and "lymphocytes" were identified by morphologic appearance (light microscopy); we recognize that discrimination between these cell types by that technique is not totally reliable $(8)$. and basophils were present. No platelets were seen on fixed smears.

Suspensions containing over $85 \%$ alveolar macrophages were lavaged from the lungs of male and female New Zealand albino rabbits with $0.15 \mathrm{M} \mathrm{NaCl}$ (10). These rabbits had received intravenous injections of complete Freund's adjuvant 2-6 wk before sacrifice (stimulated macrophages) (11). All cells were washed at least twice with $0.15 \mathrm{M} \mathrm{NaCl}$ and suspended in modified Krebs-Ringer phosphate medium, (129 mM NaCl, $5 \mathrm{mM} \mathrm{KCl}, 11 \mathrm{mM}$ sodium phosphate buffer, $1.2 \mathrm{mM} \mathrm{MgCl}$, and $0.9 \mathrm{mM} \mathrm{CaCl}_{2}$ ), $\mathrm{pH}$ 7.4. Cell counts were performed with an electronic counter (Coulter Electronics, Inc., Fine Particle Group, Hialeah, Fla.).

Lipid analysis. The fatty acid composition of the cellular phospholipids was determined as described previously (4). Cells were stored at $-70^{\circ} \mathrm{C}$ until analyzed (less than $2 \mathrm{mo}$ in all cases). The cells were extracted overnight at $4^{\circ} \mathrm{C}$ with chloroform: methanol 2:1 ( $\mathrm{vol} / \mathrm{vol})$. Total lipids were isolated from the extracts after filtration by adding $0.1 \mathrm{M}$ $\mathrm{KCl}$ and washing with theoretical upper phase (12). Total phospholipids were isolated by silicic acid chromatography, and the phospholipid fraction was transesterified with $14 \%$ $\mathrm{BF}_{3}$ in methanol for $90 \mathrm{~min}$ at $100^{\circ} \mathrm{C}$ in sealed ampules (13). The methyl esters were separated from dimethyl acetals by thin layer chromatography on silica gel $G$ plates developed with benzene, identified with 2,7-dichlorofluorescein, and eluted with chloroform. The fatty acid methyl esters were quantified by gas liquid chromatography on ethylene glycol succinate, and their identity was verified with appropriate standards (Supelco, Inc., Bellefonte, $\mathrm{Pa}$.) and chromatography on a nonpolar column (3\% polysiloxane) (4).

Because of the small amount of lipid (250-570 $\mu \mathrm{g})$ obtained from monocyte preparations, phospholipids were isolated by thin layer chromatography developed with petroleum ether-diethyl ether-acetic acid, 70:30:1 (vol/vol), scraped into Teflon-capped tubes, and transesterified with $1 \%$ sulfuric acid in methanol at $70^{\circ} \mathrm{C}$ for $60 \mathrm{~min}$. Both procedures for purifying and quantifying phospholipid fatty acids were compared, with lipids from rat liver. The two methods of isolating total phospholipids and esterification yielded identical results.

The presence or absence of an antioxidant, 2,6-di-tertbutyl-p-cresol (BHT), in all steps of the analysis, beginning with the chloroform-methanol extraction, had no effect on the fatty acid composition of rat liver phospholipids. This agent was therefore not included in the preparation of fatty acids from phagocytic cells, because it produces spurious peaks on gas liquid chromatography of purified methyl esters prepared by the $\mathrm{BF}_{3}$ method (4).

Particles for phagocytosis. Polystyrene beads, $0.9 \mu \mathrm{m}$ in diameter, (Dow Chemical Co., Midlands, Mich.) were dialyzed for $24 \mathrm{~h}$ against distilled water and then suspended at a concentration of $50 \mathrm{mg} / \mathrm{ml}$ in modified Krebs-Ringer phosphate medium, $\mathrm{pH}$ 7.4. Heat-killed $S$. epidermidis were opsonized with fresh rabbit or human serum at $37^{\circ} \mathrm{C}$ for $20 \mathrm{~min}$, washed, and suspended in the same buffer. at a concentration of $2 \times 10^{8}$ organisms $/ \mathrm{ml}$. Cholesterol linolenate and trilinolenin (Applied Science Labs., State College, $\mathrm{Pa}$.) were incorporated into paraffin oil, and emulsified with bovine albumin (Armour Pharmaceutical Co., Kankakee, I11.) as described previously (4), and the particles were opsonized with fresh human serum (14).

Production of malonyldialdehyde during phagocytosis. Cells, $2-11 \times 10^{7} / \mathrm{ml}$, were suspended in $1 \mathrm{ml}$ of Krebs- 
Ringer phosphate medium, $\mathrm{pH} 7.4$, and warmed to $37^{\circ} \mathrm{C}$ with gentle shaking. In some experiments, polystyrene beads were added to a final concentration of $0.5 \mathrm{mg} / 10^{7}$ cells. In other experiments, heat-killed opsonized $S$. epidermidis at a final ratio of five organisms/cell were added, or else 0.2 $\mathrm{ml}$ of opsonized albumin-paraffin oil particles containing cholesterol linolenate plus trilinolenin. Modified KrebsRinger phosphate medium alone was added to control suspensions. Incubations were terminated immediately or after $45 \mathrm{~min}$, when $0.5 \mathrm{ml}$ of $35 \%$ trichloroacetic acid was added. In some cases, cells and medium were separated by centrifugation at $250 \mathrm{~g}$ at $4^{\circ} \mathrm{C}$. Then $0.5 \mathrm{ml}$ of $35 \%$ trichloroacetic acid was added to the medium in the usual manner and $0.5 \mathrm{ml}$ of $18 \%$ trichloroacetic acid was added to the cell pellets. Other reagents to be assayed were mixed in suitable concentrations with $35 \%$ trichloroacetic acid. Malonyldialdehyde in the acid solutions was measured spectrophotometrically after reaction with 2 -thiobarbituric acid (TBA) ${ }^{2}$ (15). All samples were tested for absorbance at wavelengths between 440 and $560 \mathrm{~nm}$ to ascertain that a distinct peak was present at $535 \mathrm{~nm}$. The bisulfite adduct of malonyldialdehyde was synthesized from tetraethoxypropane ( $\mathrm{K}$ and $\mathrm{K}$ Laboratories, Inc., Plainview, N. Y.) by the method of Saslaw and Waravdekar (16) and was employed as a standard.

Extraction and fractionation of alveolar macrophages. 2-5 $\mathrm{ml}$ of packed rabbit alveolar macrophages was suspended with 5 vol Krebs-Ringer phosphate medium and incubated with polystyrene beads $(10-30 \mathrm{mg} / \mathrm{ml})$ for $60 \mathrm{~min}$ at $37^{\circ} \mathrm{C}$ with gentle shaking. Cells plus medium were subjected to three cycles of rapid freezing $\left(-70^{\circ} \mathrm{C}\right)$ and thawing $\left(37^{\circ} \mathrm{C}\right)$ and then centrifuged at $100,000 \mathrm{~g}$ for $1 \mathrm{~h}$ in a

${ }^{2}$ Abbreviation used in this paper: TBA, 2-thiobarbituric acid.
Beckman Model L2 ultracentrifuge (Beckman Instruments, Inc., Spinco Div, Palo Alto, Calif.). The supernatant solution was adjusted to $\mathrm{pH} 4.0$ with $0.1 \mathrm{M}$ acetic acid and the resulting precipitate was removed by centrifugation at $20,000 \mathrm{~g}$ for $30 \mathrm{~min}$. The supernatant fluids were adjusted to $\mathrm{pH} 7.0$ with $0.1 \mathrm{M} \mathrm{NaOH}$, frozen, concentrated to $2-4$ $\mathrm{ml}$ by sublimation under vacuum and then applied to $1 \times$ $90-\mathrm{cm}$ columns of Sephadex G-10 equilibrated with $2 \mathrm{mM}$ sodium phosphate buffer, $\mathrm{pH}$ 7.4. The columns were eluted with equilibration buffer and fractions of $3 \mathrm{ml}$ collected and analyzed for absorbance at $280 \mathrm{~nm}$ and for TBA reactivity. The peaks absorbing at $280 \mathrm{~nm}$, peaks with TBA reactivity, and comparable volumes of equilibration buffer were pooled, frozen, concentrated by sublimation under vacuum, thawed, and assayed for bactericidal activity. The final $\mathrm{pH}$ of all preparations was 7.0.

Preparation and analysis of malonyldialdehyde. Malonyldialdehyde was prepared from tetramethoxypropane by acid hydrolysis (17) and adjusted to $\mathrm{pH} 7.0$ with $0.01 \mathrm{M}$ sodium phosphate buffer. Linolenic acid (Eastman Organic Chemicals Div., Eastman Kodak Co., Rochester, N. Y.) was subjected to ultraviolet photolysis as described by Saslaw, Anderson, and Waravdekar (18). Aqueous extracts of the photolyzed fatty acid were prepared, filtered, and washed with carbon tetrachloride and hexane as described by Saslaw et al. (18) and adjusted to $\mathrm{pH} 7.0$ with $0.01 \mathrm{M}$ sodium phosphate buffer. Solutions were analyzed by ascending chromatography on glass plates containing silica gel $G$ (Analtech, Inc., Newark, Del.) in $n$-butanol/dichloromethane/water, $20: 4: 1$ (18). The plates were dried at room temperature, sprayed with TBA, $100 \mathrm{mg} / \mathrm{ml}$ in $35 \%$ trichloroacetic acid, and heated at $70^{\circ} \mathrm{C}$ for $5 \mathrm{~min}$. Gel filtration was performed with $1 \times 90-\mathrm{cm}$ columns of Sephadex G-10 (Pharmacia Fine Chemicals) as described by Kwon and Olcott (19).

TABLE I

Production of Malonyldialdehyde by Various Cell Types during Phagocytosis

\begin{tabular}{|c|c|c|c|c|}
\hline \multirow[b]{2}{*}{ Cells } & \multirow[b]{2}{*}{$\begin{array}{c}\text { No } \\
\text { particles }\end{array}$} & \multicolumn{3}{|c|}{ Particles } \\
\hline & & Polystyrene & S. epidermidis & $\begin{array}{l}\text { Albumin-paraffin } \\
\text { oil + linolenate }\end{array}$ \\
\hline Monocytes + lymphocytes & & \multicolumn{3}{|c|}{ nmol malonyldialdehyde/107 nucleated cells/45 min } \\
\hline Normals & $0(6)$ & $20 \pm 2(4)$ & $12 \pm 2(3)$ & NT \\
\hline Patients with idiopathic thrombocytopenic purpura & $0(2)$ & $18 \pm 4(2)$ & $10 \pm 4(2)$ & NT \\
\hline \multicolumn{5}{|l|}{ Mixed human leukocytes } \\
\hline \multicolumn{5}{|l|}{ Patients with congenital neutropenia and monocytosis } \\
\hline 1 & 0,0 & 8,25 & NT & NT \\
\hline 2 & 4 & 68 & 44 & NT \\
\hline 3 & 11 & 31 & 28 & NT \\
\hline 4 & $\mathrm{~N}^{\prime} \mathrm{T}$ & 30 & NT & N'T \\
\hline Normals & $0(12)$ & $0(12)$ & $0(4)$ & $262 \pm 15(3)$ \\
\hline \multicolumn{5}{|l|}{ Patients with chronic granulomatous disease } \\
\hline 1 & 0 & 0 & 0 & 44 \\
\hline 2 & 0 & 0 & 0 & 52 \\
\hline Purified human neutrophils & $0(5)$ & $0(5)$ & $0(3)$ & $345 \pm 41(3)$ \\
\hline
\end{tabular}

The malonyldialdehyde content of cells and medium was determined as described in the text. Means $\pm \mathrm{SEM}$ are given, or the mean and range when less than three preparations were analyzed. The number of preparations assayed are shown in the parentheses. NT, not tested. 


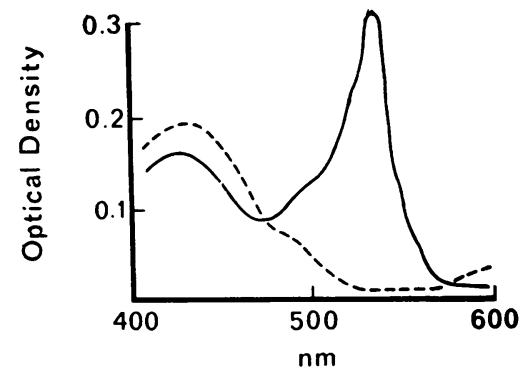

Figure 1 Absorption spectra of mixed leukocyte extracts of a patient with neutropenia and monocytosis. The leukocytes, $5 \times 10^{7} \mathrm{ml}$, were incubated for $45 \mathrm{~min}$ with (-) or without (--) polystyrene beads at $37^{\circ} \mathrm{C}$. The cells were extracted with trichloroacetic acid and the extracts were reacted with TBA as described in the text.

Measurement of bacterial activity. Staphylococcus epldermidis and Escherichia coli $\mathrm{M} 103$ (a $\mathrm{K}_{12}$ strain) were grown overnight in Trypticase soy broth (Difco Laboratories, Detroit, Mich.) at $37^{\circ} \mathrm{C}$ with gentle shaking in a water bath. The organisms were chilled and pelleted by centrifugation at $20,000 \mathrm{~g}$ for $15 \mathrm{~min}$ at $0-4^{\circ} \mathrm{C}$. The bacteria were then washed thrice by resuspension in $0.15 \mathrm{M}$ $\mathrm{NaCl}-15 \mathrm{mM}$ sodium phosphate buffer, $\mathrm{pH} 7.3$, (phosphatebuffered saline), and centrifuged as noted above. Before use, $2 \times 10^{7}$ of the organisms were incubated in a total volume of $0.6 \mathrm{ml}$ of phosphate-buffered saline with the various test solutions. At selected times, samples were removed, diluted serially in phosphate-buffered saline, and plated on trypticase soy agar for enumeration of (viable) colony-forming bacteria.

\section{RESULTS}

Production of TBA-reactive material by phagocytes during particle ingestion. Measurements of TBA-reactive material in various cell suspensions at rest and in the presence of particles are shown in Table I. Preparations of mixed leukocytes containing 69-95\% neutrophils with less than $10 \%$ monocytes from normal humans or patients with chronic granulomatous disease did not contain nor produce TBA-reactive material in the presence of polystyrene particles or heatkilled $S$. epidermidis, but generated TBA-reactive material during ingestion of particles containing linolenate. Purified normal neutrophils also produced TBA-reactive material only when incubated with the linolenate-enriched particles. Mixed blood leukocytes from patients with chronic granulomatous disease proproduced considerably less TBA-reactive material when incubated with linolenate-containing particles. As obsered previously (4), the linolenate-enriched particles alone contained TBA-reactive material but the quantity did not increase during incubations. It was less than $20 \%$ of the amount found in incubations containing normal cells and was subtracted from the final results.
Mononuclear cell fractions isolated both from normal peripheral blood freed of most platelets and from two patients with idiopathic thrombocytopenic purpura accumulated TBA-reactive material during incubations with polystyrene beads or with heat-killed S. epidermis. Mixed leukocyte suspensions from patients with neutropenia and monocytosis contained TBA-reactive material at rest in some experiments and in all instances accumulated more in the presence of polystyrene particles or heat-killed S. epidermidis. $70-80 \%$ of the TBA-reactive material made by the cell suspensions was found in the extracellular medium.

Identification of the TBA-reactive material as malonyldialdehyde. Malonyldialdehyde is considered the material responsible for the pink color formed after reaction of peroxidized polyunsaturated fatty acids with TBA (15-20). Solutions obtained from the incubation medium bathing phagocytizing rabbit alveolar macrophages or monocyte-rich suspensions from neutropenic humans (Fig. 1), chemically prepared malonyldialdehyde, and the ultraviolet photolysis products of linolenic acid had a sharp absorption peak at $535 \mathrm{~nm}$ after reaction with TBA. When chemically prepared malonyldialdehyde, extracts of oxidized linolenic acid, or extracts of phagocytizing alveolar macrophages were applied to G-10 Sephadex columns, TBA reactive peaks were obtained with identical elution volumes (Fig. 2). Malonyldialdehyde, photolyzed linolenic acid, and alveolar macrophage extracts after chromatography on G-10 Sephadex yielded two pink thiobarbituric acid-reactive spots with $R_{f} 0.6$ and 0.9 on the thin-layer chromatograms. The presence of more than one TBA-reactive spot in this solvent system has been attributed to polymerization of the malonyldialdehyde (16). Because of

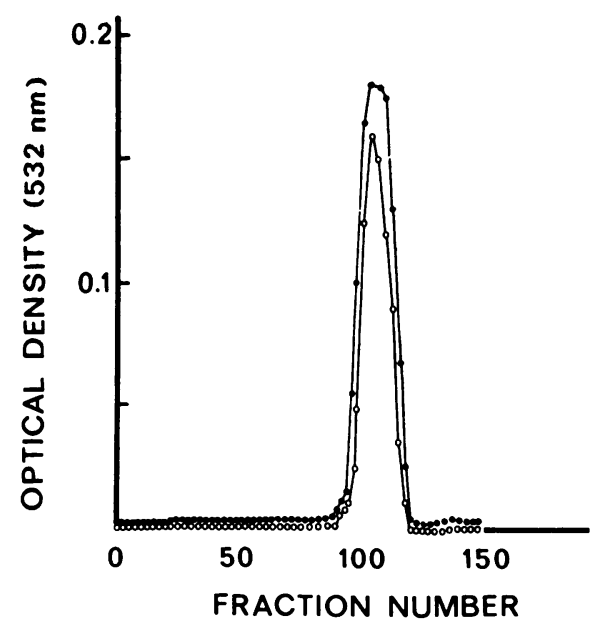

FIGURE 2 Chromatography of purified rabbit alveolar macrophage extract $(O)$ and chemically prepared malonyldialdehyde $(\bullet)$ on a $1 \times 90-\mathrm{cm}$ column of G-10 Sephadex. Fractions of $1 \mathrm{ml}$ were collected.

Lipid Peroxidation by Human Blood Phagocytes 
TABLE II

Fatty Acid Composition of Cellular Phospholipids

\begin{tabular}{cccc}
\hline $\begin{array}{c}\text { Fatty } \\
\text { acids }\end{array}$ & $\begin{array}{c}\text { Human } \\
\text { monocytes }\end{array}$ & $\begin{array}{c}\text { Purified } \\
\text { human } \\
\text { granulocytes }\end{array}$ & $\begin{array}{c}\text { Human } \\
\text { lymphocytes }\end{array}$ \\
\hline $14: 0^{*}$ & $0.8 \pm 0.1$ & $0.9 \pm 0.2$ & $0.9 \pm 0.4$ \\
$16: 0$ & $17.4 \pm 0.6$ & $20.8 \pm 0.4$ & $24.8 \pm 0.6$ \\
$16: 1$ & $1.6 \pm 0.7$ & $0.9 \pm 0.3$ & $2.0 \pm 0.1$ \\
$18: 0$ & $21.9 \pm 1.0$ & $17.9 \pm 0.4$ & $22.7 \pm 1.2$ \\
$18: 1$ & $20.2 \pm 1.3$ & $29.2 \pm 0.8$ & $15.9 \pm 1.6$ \\
$18: 2$ & $10.5 \pm 0.8$ & $11.5 \pm 0.7$ & $11.7 \pm 1.1$ \\
$20: 1$ & $\operatorname{tr}$ & $\operatorname{tr}$ & $1.6 \pm 1.6$ \\
$20: 4$ & $20.2 \pm 0.8$ & $12.4 \pm 0.6$ & $20.0 \pm 1.6$ \\
$20: 5$ & $\operatorname{tr}$ & $1.3 \pm 0.2$ & $\mathrm{NA}$ \\
$22: 4$ & $1.9 \pm 0.8$ & $1.6 \pm 0.3$ & $\mathrm{NA}$ \\
$22: 5$ & $2.8 \pm 1.1$ & $\mathrm{tr}$ & $\mathrm{NA}$ \\
$22: 6$ & $2.9 \pm 0.9$ & $\mathrm{tr}$ & $\mathrm{NA}$ \\
$24: 1$ & $\operatorname{tr}$ & $3.8 \pm 0.8$ & $\mathrm{NA}$ \\
Number of & & & \\
preparations & 3 & 5 & 2 \\
\hline
\end{tabular}

The values are the means \pm SEM for the individual preparations when three or more were analyzed or else the mean and the range and expressed as mol \%. All fatty acids which comprised more than $1 \%$ for any cell type are tabulated. tr indicates less than $0.5 \%$ NA indicates not analyzed.

* Chain length: number of double bonds.

insufficient material, extracts of human monocyte-rich preparations were not analyzed by gel filtration or thinlayer chromatography.

Fatty acid composition of cellular phospholipids. The phospholipid fatty acid composition of the different cell types analyzed is shown in Table II. When human monocytes were compared to purified granulocytes, the monocytes contained a significantly greater molar fraction of arachidonic acid in their phospholipids $(P<$ $0.001)$. Since lymphocytes were the major contaminants of monocyte-rich preparations, two preparations of lymphocytes (the nonadherent cells obtained during purification of monocytes) were analysed for phospholipid fatty acid composition. The phospholipid fatty acid composition of these cells was essentially the same as that of the monocyte-rich preparations. The most important finding was that the arachidonate concentration of the lymphocytes was not higher than that of the monocyte-enriched preparations. Therefore, the greater arachidonate content of monocytes relative to granulocytes could not be attributed to contamination by lymphocytes in the analyses.

Of the purified granulocytes, eosinophils accounted for $3-14 \%$ of the cells, but the preparations with fewest eosinophils did not differ in phospholipid fatty acid composition from those with the most eosinophils. None of the cells analyzed had significant amounts of $18: 3$ unsaturated fatty acid.

Bactericidal activity of malonyldialdehyde, and alveolar macrophage extracts. The antimicrobial effect of various fractions obtained by G-10 Sephadex column chromatography of alveolar macrophage extracts is shown in Fig. 3. Homogenates of macrophages prepared by freezing and thawing, the supernatant solution after precipitation of some proteins at $\mathrm{pH} 4.0$, and the protein-containing fractions eluted from the columns stimulated bacterial growth. The only fraction with bactericidal activity were those with elution volumes identical to malonyldialdehyde prepared chemically. The antibacterial effects of different concentrations of chemically prepared malonyldialdehyde, of aqueous extracts of peroxidized linolenic acid, and of malonyldialdehydecontaining fractions isolated from phagocytizing rabbit alveolar macrophages are shown in Fig. 4. The microbicidal activity against the two test organisms, based on molar equivalents of malonyldialdehyde, were essentially identical for the various compounds tested. Maximal bactericidal activity was observed at a concentration of $1 \mu \mathrm{mol}$ malonyldialdehyde $/ 10^{7}$ microorganisms (a concentration of $3.3 \mathrm{mM}$ ). Killing was relatively rapid under these conditions and was complete by $60 \mathrm{~min}$.

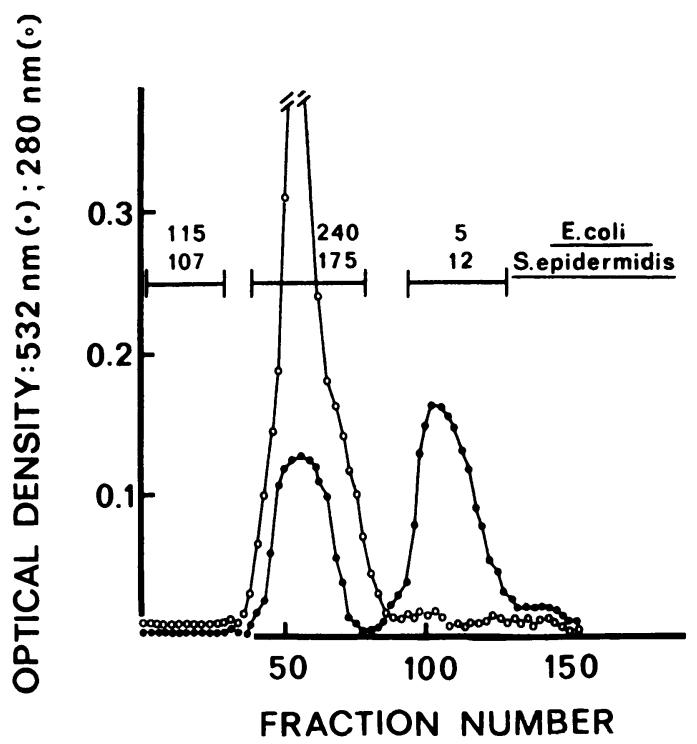

FIgURE 3 Bactericidal activity of pooled fractions eluted from Sephadex G-10 to which alveolar macrophage extract was applied. The horizontal bars indicate the fractions pooled and concentrated to equivalent volumes. TBA-reactive material in the initial peak may represent malonyldialdehyde bound to proteins. The protein-free TBA-reactive pool contained $10 \mu \mathrm{mol}$ of malonyldialdehyde. The numbers over the horizontal bars indicate the percentage of the indicated organisms remaining viable after $60 \mathrm{~min}$ of incubation in $0.5 \mathrm{ml}$ of phosphate-buffered saline to which $0.2 \mathrm{ml}$ of the pooled fractions were added. 


\section{DISCUSSION}

Lipid peroxidation occurs when oxidants attack polyunsaturated fatty acids (21-23). Human neutrophils produce hydrogen peroxide (1-3) and superoxide anion (24) during ingestion of particles. Human monocytes also generate hydrogen peroxide (25), and probably superoxide as well. Studies with rat liver microsomes, which are endowed with oxidases that peroxidize membrane lipids, suggest that hydroxyl radicals $(\mathrm{OH} \cdot)$, formed from hydrogen peroxide and superoxide by the reaction $\mathrm{O}_{2}{ }^{-} \cdot+\mathrm{H}_{2} \mathrm{O}_{2} \rightarrow \mathrm{OH} \cdot+\mathrm{OH}^{-}+\mathrm{O}_{2}$, are the species that attack unsaturated fatty acids to yield lipid hydroperoxides (26). Human monocytes ingesting inert polystyrene beads or heat-killed $S$. epidermidis accumulated malonyldialdehyde, indicating that peroxidation of endogenous lipids occurred. Human neutrophils did not accumulate malonyldialdehyde when ingesting these particles, but did so when fed particles containing linolenate. Thus, normal human neutrophils and human monocytes presumably generate hydroxyl radicals. Chronic granulomatous disease neutrophils, on the other hand, which are deficient in the synthesis of hydrogen peroxide (5) and superoxide (27), accumulated less than $20 \%$ as much malonyldialdehyde as normal neutrophils when ingesting particles containing linolenate.

The failure of human granulocytes to accumulate malonyldialdehyde during ingestion of polystyrene beads or heat-killed $S$. cpidermidis suggested that these cells might have fewer polyunsaturated fatty acids in their membranes than human monocytes. In fact, monocytes contained more arachidonate in their phospholipids than granulocytes. However, the failure to detect malonyldialdehyde does not mean that peroxidation of membrane lipids did not occur in human granulocytes. Human granulocytes contained considerably more arachidonate than guinea pig granulocytes, analyzed previously, which had lipid hydroperoxides in their phagosomes (4). The saturation of membrane fatty acids in peripheral leukocytes of patients with chronic myelogenous leukemia increased after phagocytosis of particles by the cells, suggesting that they were subjected to peroxidation (28). Malonyldialdehyde formation reflects only a small fraction of the lipid peroxidation that occurs in tissues (22). It is a labile compound that reacts with proteins $(22,29)$. Accordingly, the bulk of the malonyldialdehyde found in association with phagocytizing monocytes was in the extracellular medium and presumably represented only a minor portion of the total aldehyde produced. The net amount of lipid peroxidized in a tissue reflects the balance between production and catabolism of the peroxides. Antioxidants such as tocopherol (30), levels of ascorbic acid (31), undefined inhibitors (32), and reduction of lipid peroxides by



Figure 4 Effect of concentration of malonyldialdehyde or malonyldialdehyde equivalents on the bactericidal activity after $60 \mathrm{~min}$ of incubation at $37^{\circ} \mathrm{C}$. Microorganism concentration was $10^{7} / \mathrm{ml}$. A. aqueous extracts of peroxidized linolenate; B. malonyldialdehyde prepared from tetramethoxypropane; C. pooled fractions with bactericidal activity from chromatography of alveolar macrophage extracts. The circles represent the mean and the bars the SEM of three separate experiments.

reduced glutathione $(33,34)$ in tissues may all influence the degree of lipid peroxidation and the quantity of hydroperoxides catabolized to malonyldialdehyde. The relative contributions of these factors in human monocytes and granulocytes remain to be determined.

Platelet membranes are richly endowed with arachidonate (35) and intact platelets produce malonyldialdehyde when incubated with polystyrene beads (36). Although it is possible that platelets may have provided a minor contribution to our results, a number of factors indicate that they were not a major factor. After centrifugation at low speeds, fewer than 1 platelet/two nucleated cells was present in the final cell suspensions prepared for assessment of malonyldialdehyde formation during ingestion. No platelets were seen in the final mononuclear cell samples prepared for lipid analyses. Mononuclear cell fractions from patients with idiopathic thrombocytopenic purpura, whose blood contained less than 20,000 platelets $/ \mathrm{mm}^{3}$, generated quantities of malonyldialdehyde in the presence of polystyrene beads and $S$. epidermidis that did not differ from those produced by mononuclear cell fractions from normal blood. Finally, mixed leukocyte suspensions from patients with neutropenia and monocytosis produced malonyldialdehyde in the presence of phagocytizable particles, whereas leukocyte preparations from normal individuals with neutrophils predominating, yet with

Lipid Peroxidation by Human Blood Phagocyles 
equivalent numbers of platelets, did not generate the aldehyde.

The bactericidal activity of fats treated with ultraviolet radiation was recognized over 40 years ago (37). The antimicrobial principle in these oils was unknown, but it was thought that radicals resulting from lipid peroxidation might be involved (38). In this study, preparations containing malonyldialdehyde, one of the products of lipid peroxidation, had bactericidal activity for E. coli M103 and S. epidermidis. Chemically prepared malonyldialdehyde, aqueous extracts of peroxidized linolenic acid, and extracts of phagocytizing alveolar macrophages containing malonyldialdehyde also had bactericidal activity against these microorganisms. The manner in which malonyldialdehyde might exert bactericidal action is unknown, but malonyldialdehyde has a variety of toxic effects, including binding to DNA $(39,40)$, inhibition of growth of cultured fibroblasts (40), and inactivation of a number of enzymes (41), all probable manifestations of its alkylating potential. The malonyldialdehyde preparation from diverse sources used in our experiments are probably mixtures of the dialdehyde, polymers, and unknown contaminants. Thus it cannot be concluded that malonyldialdehyde is the only agent in the test reagents with bactericidal power. However, it is of interest that the antibacterial activities were equivalent to that of authentic malonyldialdehyde, when compared on a molar basis. The quantities of malonyldialdehyde detected in association with phagocytizing cells are probably underestimates of the actual amounts produced due to the reactivity of aldehyde group. The presence of most of the measurable malonyldialdehyde in the extracellular medium is consistent with this view. This does not negate the potential of malonyldialdehyde to have bactericidal activity in the cell, as the concentration of malonyldialdehyde might be high within the narrow confines of the phagocytic vesicle, the site of bacterial entrapment. Although malonyldialdehyde has been identified in association with isolated phagocytic vesicles from rabbit alveolar macrophages (4), the concentration within that structure in the intact cell is unknown. It is also possible that other reaction products accumulate during lipid peroxidation (42), which may also be bactericidal.

From the results of the studies of cells from patients with chronic granulomatous disease, it is clear that little peroxidation of ingested lipid occurs during phagocytosis in the absence of a peroxide-generating system. Therefore, the bactericidal role of lipid peroxidation in vivo, if any, must be to potentiate the activity of hydrogen peroxide and other radicals. Polymorphonuclear leukocytes from many species utilize myeloperoxidase and halide ions to enhance the microbicidal effect of hydrogen peroxide (43). Human monocytes, relative to granulocytes, are deficient in myeloperoxidase (25), and might use toxic products of their more intense lipid peroxidation to potentiate the bactericidal activity of hydrogen peroxide.

\section{ACKNOWLEDGMENTS}

This work was supported by grants from the U. S. Public Health Service: AI-08173 and CA-13472.

\section{REFERENCES}

1. Karnovsky, M. L. 1968. The metabolism of leukocytes. Sem. Hematol. 5 : 156-165.

2. Klebanoff, S. J. 1971. Intraleukocyte microbicidal defects. Annu. Rev. Med. 22: 39-62.

3. Strauss, R. R., B. B. Paul, A. A. Jacobs, and A. J. Sbarra. 1971. Role of the phagocyte in host-parasite interactions. XXVII. Myeloperoxidase $-\mathrm{H}_{2} \mathrm{O}_{2}-\mathrm{Cl}^{-}$-mediated aldehyde formation and its relationship to antimicrobial activity. Infect. Immun. 3: 595-602.

4. Mason, R. J., T. P. Stossel, and M. Vaughan. 1972. Lipids of alveolar macrophages, polymorphonuclear leukocytes, and their phagocytic vesicles. J. Clin. Invest. 51: 2399-2407.

5. Holmes, B., A. R. Page, and R. A. Good. 1967. Studies of the metabolic activity of leukocytes from patients with a genetic abnormality of phagocytic function. J. Clin. Invest. 46: 1422-1432.

6. Stossel, T. P. 1973. Evaluation of opsonic and leukocyte function with a spectrophotometric test in patients with infection and with phagocytic disorders. Blood J. Hematol. 42: 121-130.

7. Böyum, A. 1968. Isolation of mononuclear cells and granulocytes from human blood. Scand. J. Clin. Lab. Invest. Suppl. 97 : 77-89.

8. Zucker-Franklin, D. 1974. The percentage of monocytes among "mononuclear" cell fractions obtained from normal human blood. J. Immunol. 112: 234-240.

9. Mickenberg, I. D., R. K. Root, and S. M. Wolff. 1970. Leukocytic function in hypogammaglobulinemia. J. Clin. Invest. 49: 1528-1538.

10. Myrvik, Q. N., E. S. Leake, and B. Fariss. 1961. Studies on pulmonary alveolar macrophages from the normal rabbit: a technique to procure them in a high state of purity. J. Immunol. $86: 128-132$.

11. Moore, R. D., and M. D. Schoenberg. 1964. The response of histiocytes and macrophages in the lungs of rabbits injected with Freund's adjuvant. Br. J. Exp. Pathol. 45: 488-497.

12. Folch, J., M. Lees, and G. H. Sloan Stanley. 1957. A simple method for the isolation and purification of total lipides from animal tissues. J. Biol. Chem. 226: 497509.

13. Morrison, W. R., and L. M. Smith. 1964. Preparation of fatty acid methyl esters and dimethylacetals from lipids with boron fluoride-methanol. J. Lipid Res. 5: 600-608.

14. Stossel, T. P. 1973. Quantitative studies of phagocytosis. Kinetic effects of cations and of heat-labile opsonin. J. Cell Biol. 58: 346-356.

15. Ottolenghi, A. 1959. Interaction of ascorbic acid and mitochondrial lipides. Arch. Biochem. Biophys. 79: $355-363$ 
16. Saslaw, L. D., and V. S. Waravdekar. 1957. Preparation of malondialdehyde bis-bisulfite, sodium salt. J. Org. Chem. 22: 843-844.

17. Kwon, T-W., and B. M. Watts. 1963. Determination of malondialdehyde by ultraviolet spectrophotometry. J. Food Sci. 28: 627-630.

18. Saslaw, L. D., H. J. Anderson, and V. S. Waravdekar. 1963. Ultra-violet photolysis of unsaturated fatty acids in relation to the thiobarbituric acid test. Nature (Lond.). 200: 1098-1099.

19. Kwon, T-W., and H. S. Olcott. 1966. Malonaldehyde from the autoxidation of methyl linolenate. Nature (Lond.). 210: 214-215.

20. Sinnhuber, R. L., and T. C. Yu. 1958. Characterization of the red pigment formed in the 2-thiobarbituric acid determination of oxidative rancidity. Food Res. 23: 626-633.

21. Hochstein, P., and L. Ernster. 1963. ADP-activated lipid peroxidation coupled to the TPNHI oxidase system of microsomes. Biochem. Biophy's. Res. Commun. 12: 388-394.

22. Barber, A. A., and F. Bernheim. 1967. Lipid peroxidation: its measurement, occurrence, and significance in animal tissues. Adv. Gerontol. Res. 2: 355-403.

23. May, H. E., and P. B. McCay. 1968. Reduced triphosphopyridine nucleotide oxidase-catalyzed alterations of membrane phospholipids. I. Nature of the lipid alterations. J. Biol. Chem. 243: 2288-2295.

24. Babior, B. M., R. S. Kipnes, and J. T. Curnutte. 1973. Biological defense mechanisms: the production by leukocytes of superoxide, a potential bactericidal agent. $J$. Clin. Invest. 52 : 741-744.

25. Baehner, R. L., and R. B. Johnston, Jr. 1972. Monocyte function in children with neutropenia and chronic infections. Blood J. Hematol. 40: 31-41.

26. Fong, K-L., P. B. McCay, J. L. Poyer, B. B. Keele, and H. Misra. 1973. Evidence that peroxidation of lysosomal membranes is initiated by hydroxy free radicals produced during flavin enzyme activity. J. Biol. Chem. 248: 7792-7797.

27. Curnutte, J. T., D. M. Whitten, and B. M. Babior. 1974. Defective superoxide production by granulocytes from patients with chronic granulomatous disease. $N$ Engl. J. Med. 290: 593-597.

28. Smolen, J. E., and S. B. Shohet. 1974. Remodeling of granulocyte membrane fatty acids during phagocytosis. J. Clin. Invest. 53: 726-734.

29. Barber, A. A. 1961. Inhibition of lipid peroxide formation by vertebrate blood serum. Arch. Biochem. Biophy's. 92: 38-43.
30. McCay, P. B., J. L. Poyer, P. M. Pfeifer, H. E. May, and J. M. Gilliam. 1971. A function for $\alpha$-tocopherol: stabilization of the microsomal membrane from radical attack during TPNH-dependent oxidations. Lipids. 6: 297-306.

31. Grinna, L. S., and A. A. Barber. 1973. Lipid peroxidation in livers and kidneys from young and old rats. Biochem. Biophys. Res. Commun. 55: 773-779.

32. Wills, E. D. 1966. Mechanisms of lipid peroxide formation in animal tissues. Biochem. J. 99: 667-676.

33. Christophersen, B. O. 1968. The inhibitory effect of reduced glutathione on the lipid peroxidation of the microsomal fraction and mitochondria. Biochcm. J. 106: 515-522.

34. Khandwala, A., and J. B. L. Gee. 1973. Linolenic acid hydroperoxide: impaired bacterial uptake by alveolar macrophages, a mechanism of oxidant lung injury. Science (Wash. D. C.). 182: 1364-1365.

35. Marcus, A. J., H. L. Ullman, and L. B. Safier. 1969. Lipid composition of subcellular particles of human blood platelets. J. Lipid Res. 10: 108-114.

36. Okuma, M., M. Steiner, and M. G. Baldini. 1971. Studies on lipid peroxides in platelets. II. Effect of aggregating agents and platelet antibody. J. Lab. Clin. Med. 77 : 728-742.

37. Harris, R. S., J. M. Bunker, and N. A. Milas. 1932. The germicidal activity of vapors from irradiated oils. J. Bacteriol. 23 : 429-435.

38. Harris, R. S., J. W. M. Bunker, and N. A. Milas. 1932. Chemical nature of germicidal vapors emanating from irradiated oils. Ind. Eng. Chem. 24: 1181-1183.

39. Brooks, B. R., and O. L. Klamerth. 1968. Interaction of DNA with bifunctional aldehydes. Eur. J. Biochem. 5: 178-182.

40. Reiss, U., A. L. Tappel, and K. S. Chio. 1972. DNAmalonaldehyde reaction: formation of fluorescent products. Biochem. Biophy's. Res. Commun. 48: 921-926.

41. Chio, K. S., and A. L. Tappel. 1969. Inactivation of ribonuclease and other enzymes by peroxidizing lipids and by malonaldehyde. Biochemistry. 8: 2827-2832.

42. Pfeifer, P. M., and P. B. McCay. 1971. Reduced triphosphopyridine nucleotide oxidase-catalyzed alterations of membrane phospholipids. V. Use of erythrocytes to demonstrate enzyme-dependent production of a component with the properties of a free radical. J. Biol. Chem. 246: 6401-6408.

43. Klebanoff, S. J. 1967. Iodination of bacteria : a bactericidal mechanism. J. Exp. Med. 126: 1063-1078. 